\title{
Modeling heat stress effect on Holstein cows under hot and dry conditions: Selection tools
}

\author{
M. J. Carabaño, ${ }^{* 1}$ K. Bachagha, ${ }^{*}$ M. Ramón, † and C. Díaz* \\ *Departamento de Mejora Genética Animal, Instituto Nacional de Investigación y Tecnología Agraria y Alimentaria (INIA), Madrid 28040, Spain \\ †Centro Regional de Selección y Reproducción Animal, 13300 Valdepeñas, Spain
}

\begin{abstract}
Data from milk recording of Holstein-Friesian cows together with weather information from 2 regions in Southern Spain were used to define the models that can better describe heat stress response for production traits and somatic cell score (SCS). Two sets of analyses were performed, one aimed at defining the population phenotypic response and the other at studying the genetic components. The first involved 2,514,762 test-day records from up to 5 lactations of 128,112 cows. Two models, one fitting a comfort threshold for temperature and a slope of decay after the threshold, and the other a cubic Legendre polynomial (LP) model were tested. Average $\left(\mathrm{T}_{\mathrm{AVE}}\right)$ and maximum daily temperatures were alternatively considered as covariates. The LP model using $\mathrm{T}_{\mathrm{AVE}}$ as covariate showed the best goodness of fit for all traits. Estimated rates of decay from this model for production at 25 and $34^{\circ} \mathrm{C}$ were 36 and 170 , 3.8 and 3.0, and 3.9 and $8.2 \mathrm{~g} / \mathrm{d}$ per degree Celsius for milk, fat, and protein yield, respectively. In the second set of analyses, a sample of 280,958 test-day records from first lactations of 29,114 cows was used. Random regression models including quadratic or cubic LP regressions (TEM_) on $\mathrm{T}_{\mathrm{AVE}}$ or a fixed threshold and an unknown slope (DUMMY), including or not cubic regressions on days in milk (DIM3_), were tested. For milk and SCS, the best models were the DIM3 models. In contrast, for fat and protein yield, the best model was TEM3. The DIM3DUMMY models showed similar performance to DIM3TEM3. The estimated genetic correlations between the same trait under cold and hot temperatures $(\rho)$ indicated the existence of a large genotype by environment interaction for fat $(\rho$ $=0.53$ for model TEM3) and protein yield ( $\rho$ around 0.6 for DIM3TEM3) and for SCS $(\rho=0.64$ for model DIM3TEM3), and a small genotype by environment interaction for milk ( $\rho$ over 0.8 ). The eigendecomposition of the additive genetic covariance matrix from model TEM3 showed the existence of a dominant component,
\end{abstract}

Received February 6, 2014.

Accepted August 14, 2014.

${ }^{1}$ Corresponding author: mjc@inia.es a constant term that is not affected by temperature, representing from $64 \%$ of the variation for SCS to $91 \%$ of the variation for milk. The second component, showing a flat pattern at intermediate temperatures and increasing or decreasing slopes for the extremes, gathered 15,11 , and $24 \%$ of the variation for fat and protein yield and SCS, respectively. This component could be further evaluated as a selection criterion for heat tolerance independently of the production level.

Key words: Holstein cattle, heat stress, genetic selection

\section{INTRODUCTION}

The climate of a large proportion of the Iberian Peninsula is classified as temperate with dry and hot summers, or as hot steppe. More than half of the Peninsula surface presents monthly average maximum daily temperatures in July and August well over $30^{\circ} \mathrm{C}$ (AEMET, 2011). Climate change is expected to worsen the temperature situation over the next decades. Segnalini et al. (2013) predicted that, by 2050, large areas of the center, south, and northeast of the Iberian Peninsula will reach, according to the predicted values of temperature-humidity indices (THI), discomfort (72 $\leq$ THI $<75)$ and alert conditions $(75 \leq$ THI $<79)$ for livestock in the summer months. These conditions will also affect most of the Mediterranean basin and might extend to more northern latitudes. A significant proportion of the dairy cattle farms in Spain (around $20 \%$ ) is located in these areas. Similar hot and dry climate conditions affect or will affect other large areas of the planet and their milk production industry. Selection of animals tolerant to heat stress without altering their potential for milk production might be needed to support the dairy cattle industry under hot weather conditions.

Several studies have previously dealt with the determination of the effect of heat stress on milk production and the estimation of genetic components of heat stress resistance. Misztal (1999) proposed a model fitting a comfort zone, with no effect of temperature on production, followed by a linear decay in production, providing 2 parameters: the thermotolerance threshold and the 
subsequent slope of decay for each animal in the most complex model (Sánchez et al. 2009b). Bernabucci et al. (2014) followed a similar approach through the use of a dummy covariable and fixing a comfort threshold equal for all animals a priori. This type of model is attractive because of the direct biological interpretation of the parameters obtained for each animal. However, it relies on strong assumptions, such as that production decays abruptly after the threshold, that the decay is then linear, and, in the simplest versions, that a common known or unknown comfort threshold exists for all animals. In the most parameterized model, where individual threshold and slopes are fitted, slow mixing and convergence rates have been observed (Sánchez et al., 2009a). Moreover, the parameters representing the overall level of production (intercept) and the tolerance to heat stress (slope) are genetically antagonistic (Ravagnolo and Misztal, 2000; Sánchez et al., 2009a; Bernabucci et al., 2014), which indicates that selection for the tolerance parameter is likely to result in a decrease in the production level and vice versa. Alternatively, Brügemann et al. (2011) have used random regressions to fit both the effects of DIM and THI on production traits. Random regression parameters lack biological interpretation, but these models are attractive for 2 reasons. First, they have large flexibility to fit smoother patterns of decay and, second, they allow the use of eigendecomposition of the additive genetic covariance matrix to find selection criteria (as in Kirkpatrick et al., 1990). Such selection criteria are not correlated among themselves and could help in the improvement of tolerance to heat stress with no effect on production level. For test-day models used for selection on production, one of these eigenfunctions has been associated with the persistency of lactations. This eigenfunction has been also advocated as a selection criterion for this trait to avoid the problems of the antagonistic relationship between production level and other persistency measures (see, for example, Togashi and Lin, 2006). Both approaches, which we have named the splines $(\mathbf{S P})$ model of Misztal (1999) and the random regression reaction norm model based on Legendre polynomials (LP), have not been formally compared until now.

This study aimed at defining the models that can best predict the population response and the individual genetic components of heat tolerance, using data from Spanish Holstein-Friesian farms under hot and dry conditions. Possibilities of selection for heat tolerance independent from production level are also explored.

\section{MATERIALS AND METHODS}

Production and SCC data as well as pedigree information were provided by the Confederation of the
Spanish Friesian Associations (CONAFE; Madrid, Spain). Weather records were provided by the meteorological state agency [Agencia Estatal de Meteorología (AEMET), Madrid, Spain]. The production and SCC database consisted of test-day records from the first 5 lactations of Spanish Holstein cows calving between 2002 and 2012 in Castile la Mancha and Andalusia. These regions were chosen because they are the areas of highest summer temperatures in Spain.

For SCC, SCS were obtained using the following expression (Ali and Shook, 1980):

$$
\mathrm{SCS}=\log _{2}(\mathrm{SCC} / 100)+3 .
$$

After filtering for abnormal records of production, SCC and environmental indicators, the final data set comprised information on test-day milk, fat, and protein yields and SCS records of 2,514,762 test-day records from 128,112 cows in 568 herds from 2002 to 2012 , inclusive.

Concerning the weather stations, records from 718 stations in both regions (Castile la Mancha and Andalusia) were provided by AEMET. Not all weather stations collect humidity data. Therefore, the average distance between weather stations from which THI could be calculated and farms was larger than for stations providing only temperatures. For temperature, the average distance was $7.24 \mathrm{~km}$, with a maximum of $29.65 \mathrm{~km}$ and a standard deviation of 5.0, whereas the average distance for stations where THI could be obtained was $13.29 \mathrm{~km}$, with a maximum of $29.98 \mathrm{~km}$ and a standard deviation of $7.90 \mathrm{~km}$. Temperature-humidity indices were highly correlated with temperatures and showed an almost identical pattern of change as did temperatures alone along the year (data not shown). Thus, due to the high similarity between temperature and THI and the fact that stations with humidity records were at a greater distance from herds than stations with only temperature records, daily average $\left(\mathbf{T}_{\mathrm{AVE}}\right)$ and maximum ( $\left.\mathbf{T}_{\mathrm{MAX}}\right)$ temperatures were used in the subsequent analyses to avoid lack accuracy in the estimates of responses to different heat loads.

Two sets of analyses were performed. The first one dealt with the estimation of the response to increasing heat loads for production traits and SCS at the population level. The second set of analyses aimed at modeling the individual genetic components of response to heat in this population.

\section{Reaction Norm of Production to Temperature Increase: Population Level}

The whole data set described previously was used in this part of the study. Two types of models were fitted: 
the SP and the LP models. In SP models, 2 splines are fitted. The first corresponds to the comfort region, where production or SCS remain unaffected by temperature. The second one describes the stress region, where production and SCS follow a linear decay or increase with temperature. The point where the 2 splines meet is the thermotolerance threshold. For LP, cubic functions were fitted to define the pattern of response to increasing temperatures.

The general model used to determine the effect of temperature on productive traits and SCS at the population level had the following general form:

$$
\mathrm{y}_{\mathrm{ijk} \_\mathrm{T}}=\mathrm{HY}_{\mathrm{i}}+\mathrm{LADIM}_{\mathrm{j}}+\mathrm{f}(\mathrm{T})+\mathrm{c}_{\mathrm{k}}+\mathrm{e}_{\mathrm{ijk} \_\mathrm{T}},
$$

where $y_{\mathrm{ijk} \_\mathrm{T}}$ is the observation for a given trait at a certain temperature $\mathrm{T} ; \mathrm{HY}_{\mathrm{i}}$ is the herd-year of calving systematic effect (3,712 levels); LADIMj is the lactation-age at calving-DIM systematic effect (533 levels), and classes were defined as in the national evaluation model for these traits; $f(T)$ is a function of temperature $\left(\mathrm{t}=\mathrm{T}_{\mathrm{AVE}}\right.$ or $\left.\mathrm{T}_{\mathrm{MAX}}\right)$, that differs between $\mathrm{SP}$ and $\mathrm{LP}$ models; $c_{k}$ is a cow effect, a priori assumed to be independently and identically distributed (i.i.d.) as $\mathrm{N}\left(0, \sigma_{\mathrm{c}}^{2}\right)$, where $\sigma_{\mathrm{c}}^{2}$ is the variance of cow effects $(128,112$ levels); and $e_{i j k_{-} T}$ is the residual effect, with $e_{i j k \_T}$ i.i.d. as $\mathrm{N}\left(0, \sigma_{\mathrm{e}}^{2}\right)$, where $\sigma_{\mathrm{e}}^{2}$ is the residual variance.

For SP models,

$$
f(t)=\left\{\begin{array}{c}
0 \text { if } T<T_{0} \\
b\left(T-T_{0}\right), \text { otherwise }
\end{array},\right.
$$

where $b$ is the slope of response to temperature increases and $T_{o}$ is the thermotolerance threshold.

For LP models,

$$
f(T)=\sum_{i=0}^{q} b_{i} Z_{i}(T)
$$

where $b_{i}$ are regression coefficients, $Z_{i}(T)$ are the covariates of the Legendre polynomials of order $q(q=3)$, evaluated at the corresponding standardized values of the $\mathrm{T}$ variables in the interval -1 to 1 . In the LP models, the maxima and derivatives (slopes) of the polynomial functions at given temperatures were obtained as proxies for the threshold and slope in the SP models.

The inferential method implemented for estimating parameters for SP and LP models was a Bayesian Markov-chain Monte Carlo procedure, through a Gibbs sampler algorithm. For the SP models, a MetropolisHastings sampling within the Gibbs sampler was used to obtain samples for the threshold $T_{0}$, which did not have a known conditional distribution. A software pro- gram written in the Fortran 90 language, provided by J. P. Sánchez (Genètica i millora animal, IRTA, Torre Marimon, 08140 Caldes de Montbui, Barcelona, Spain; personal communication), was used in the estimation of the unknowns in the SP models. This program uses a Gibbs sampling-Bayesian approximation to obtain posterior distribution features for the unknown parameters in the SP model. For the threshold, whose conditional posterior distribution did not have a closed form, a Metropolis-Hastings approach within the Gibbs sampler was followed to obtain the conditional samples. In each iteration, the threshold is sampled using a Gaussian proposal density centered on the previous value of the threshold. For the LP models, the Gibbsf90 package (Misztal et al., 2002) was used. A single long chain of 3,000 samples was generated for both models. The first 1,000 samples were discarded as burn-in, and the remaining samples were used to compute posterior means of the model's parameters. Convergence of Gibbs chains was monitored by visual inspection of plots of samples and the convergence criteria provided by the boa package (v 1.1.7-2; Smith, 2007) of R (The R Foundation for Statistical Computing, Vienna, Austria). For each parameter, the mean and the $95 \%$ high posterior density intervals (HPD95\%) were also calculated using this package.

Overall, 4 models (SP or LP models using either $\mathrm{T}_{\mathrm{AVE}}$ or $\mathrm{T}_{\mathrm{MAX}}$ ) were fitted for each trait. Models were compared according to their goodness of fit, measured through the deviance information criterion (DIC; Spiegelhalter et al., 2002) provided by the software used to estimate the unknowns in each model.

\section{Reaction Norm of Production to Temperature Increase: Individual Genetic and Environmental Components}

To obtain a more tractable data from a computation point of view for this analysis, a random sample of $30 \%$ of the herds was obtained. From all records in the sampled herds, first-lactation records were then selected to avoid the complexity of models including test-day records from different lactations. The data set used in this part of the study contained 280,958 testday records from 29,914 Spanish Holstein cows in 139 herds, covering the same period of time as for the whole data set (2002 to 2012).

A pedigree file was constructed using genealogical information provided by the Confederation of the Spanish Friesian Associations. Ancestors of the animals with data were traced back 3 generations (up to the great grandparents). The final genealogical file contained 64,922 animals, progeny of 3,158 bulls, and 8,534 dams with more than 1 progeny. The minimum, median, and 
maximum of the paternal half sib family sizes were 2 , 5 , and 677 , respectively.

Several models were analyzed and compared under a Bayesian framework for each trait-temperature combination. The most complex models included cubic random regressions on DIM and a reaction norm function on temperature. Reduced models included only the reaction norm on temperature. A model fitting only a cubic function on DIM, which would be equivalent to current test-day models used in genetic evaluations in dairy cattle, was also analyzed.

The general model equation for the most complex models was as follows:

$$
\begin{aligned}
& \mathrm{y}_{\mathrm{ijk} \_} \mathrm{DT}=\mathrm{HYS}_{\mathrm{i}}+\mathrm{ADIM}_{\mathrm{j}}+\sum_{\mathrm{q}=0}^{3} \mathrm{~b}_{\mathrm{q}} \mathrm{Z}_{\mathrm{q}}(\mathrm{T})+\sum_{\mathrm{r}=0}^{3} \mathrm{a}_{\mathrm{rk}}^{\mathrm{DIM}} \mathrm{Z}_{\mathrm{r}}(\mathrm{D}) \\
& +\sum_{\mathrm{r}=0}^{3} \mathrm{p}_{\mathrm{rk}}^{\mathrm{DIM}} \mathrm{Z}_{\mathrm{r}}(\mathrm{D})+\mathrm{f}\left[\mathrm{a}_{\mathrm{sk}}^{\mathrm{T}}, \mathrm{Z}_{\mathrm{s}}(\mathrm{T})\right]+\mathrm{f}\left[\mathrm{p}_{\mathrm{sk}}^{\mathrm{T}}, \mathrm{Z}_{\mathrm{s}}(\mathrm{T})\right]+\mathrm{e}_{\mathrm{ijk} \_\mathrm{DT}},
\end{aligned}
$$

where $\mathrm{y}_{\mathrm{ijk} \_\mathrm{DT}}$ is the observation for a given trait at a certain $\mathrm{DIM}=\mathrm{D}$ and temperature $\left(\mathrm{T}_{\mathrm{AVE}}\right.$ or $\left.\mathrm{T}_{\mathrm{MAX}}\right)=\mathrm{T}$; $\mathrm{HYS}_{\mathrm{i}}$ is the herd-year-season of test day, with seasons being defined as from January to March, April to June, July to September, and October to December $(3,899$ levels for milk and SCS, 3,898 levels for fat yield, and 3,897 levels for protein yield); ADIMj is the age-DIM (130 levels) effect; $b_{\mathrm{q}}(\mathrm{q}=0, \ldots, 3)$ are regression coefficients for temperature, $\mathrm{Z}_{\mathrm{q}}(\mathrm{T})$ are the covariates of the qth Legendre polynomial evaluated at temperature $\mathrm{T} ; \mathrm{a}_{\mathrm{rk}}^{\mathrm{DIM}}$ and $\mathrm{p}_{\mathrm{rk}}^{\mathrm{DIM}}(\mathrm{r}=0, \ldots, 3)$ are the additive genetic and permanent environmental random regression coefficients for DIM for animal $\mathrm{k}$, respectively; $\mathrm{Z}_{\mathrm{r}}(\mathrm{D})$ ( $\mathrm{r}$ $=0, \ldots, 3)$ are the covariates of the rth Legendre polynomial evaluated at $\mathrm{D}$; and $\mathrm{f}\left[\mathrm{a}_{\mathrm{sk}}^{\mathrm{T}}, \mathrm{Z}_{\mathrm{s}}(\mathrm{T})\right]$ and $\mathrm{f}\left[\mathrm{p}_{\mathrm{sk}}^{\mathrm{T}}, \mathrm{Z}_{\mathrm{s}}(\mathrm{T})\right]$ are regression functions describing the reaction norm of additive genetic $\left(\mathrm{a}_{\mathrm{sk}}\right)$ and permanent environmental $\left(\mathrm{p}_{\mathrm{sk}}\right)$ components of traits to temperature T. Two types of functions were used, Legendre polynomials (both quadratic and cubic) on temperatures (TEM2 and TEM3) or linear regressions on a dummy variable (DUMMY) that took zero values for temperatures below a predefined threshold and temperature minus the threshold above the threshold (as in Bernabucci et al., 2014). Residual effects $\mathrm{e}_{\mathrm{ijk} \_ \text {DT }}$ were assumed to be i.i.d. as $\mathrm{N}\left(0, \sigma_{\mathrm{e}}^{2}\right)$. Homogeneous residual variance was assumed across temperatures and DIM. Average contemporary group size (for HYS) was 70, ranging from 5 to 716 records per class.

Overall, 7 models were fitted for each trait-temperature combination. These were models including random regressions both on DIM and temperature (DIM3TEM3,
DIM3TEM2, and DIM3DUMMY, called DIM3_ models), reduced models including only regressions on temperature (TEM3, TEM2, called TEM_ models, and DUMMY) and the reference test-day model with no temperature regressions (DIM3).

The (co)variance structures for regression coefficients for individual animals for both the regressions on DIM and temperature were assumed to be

$$
\operatorname{var}(\mathbf{a})=\mathbf{G}=\mathbf{G}_{\mathrm{o}} \otimes \mathbf{A} ; \operatorname{var}(\mathbf{p})=\mathbf{P}=\mathbf{P}_{\mathrm{o}} \otimes \mathbf{I},
$$

where $\mathbf{a}$ and $\mathbf{p}$ are vectors of additive genetic and permanent environmental coefficients for all animals, respectively; $\mathbf{G}_{\circ}$ and $\mathbf{P}_{\mathrm{o}}$ are the additive genetic and permanent environmental (co)variances for all the regression coefficients, respectively; and $\mathbf{I}$ is an identity matrix. The dimension of $\mathbf{G}_{\mathrm{o}}$ and $\mathbf{P}_{\mathrm{o}}$ matrices varied, depending on the function used to describe the reaction norm and whether or not the model included random regressions on DIM. The minimum dimensions were 2 $\times 2$ for the DUMMY model and the maximum dimensions were $7 \times 7$ for the DIM3TEM3 model.

The additive genetic deviation for individual animals and the additive and permanent environmental variances at a given temperature or DIM were computed from the estimated solutions for genetic regression coefficients and the estimated (co)variance matrices, as in Jamrozik and Schaeffer (1997). Estimates of genetic parameters (heritability and correlations) at different temperature or DIM points were obtained from the estimated (co)variances. Eigenvalues, eigenvectors, and eigenfunctions of the estimated (co)variance matrices for the TEM3 model were obtained to explore the possibility of alternative selection criteria for heat tolerance, independent from production level.

A Bayesian approach via Gibbs sampling was used to obtain samples from marginal posterior distributions of the parameters of interest with software written in the Fortran 90 language (López-Romero et al., 2003). A total of 100,000 iterations were run, with 30,000 discarded as burn-in. Post-Gibbs analyses were performed using the boa package of R (v 1.1.7-2; Smith, 2007). Convergence of Gibbs chains was monitored by visual inspections of plots of samples and from the convergence information provided by the boa package.

The described models were compared according to the goodness of fit, using the natural logarithm of the marginal density (LMD), and by the predictive ability of future data, using a checking function that measures the expected difference (D) under the predictive distribution between an observation excluded from the total data to fit the model and its prediction. Both statistics were calculated by the program used to estimate ge- 
Table 1. Mean, SD, 1st and 99th percentiles for milk production and composition and SCC, and number of animals and records available for the study

\begin{tabular}{lccccc}
\hline Item & Mean & SD & $\begin{array}{c}\text { Percentile } \\
(1 \text { st-99th })\end{array}$ & $\begin{array}{c}\text { No. of } \\
\text { animals }\end{array}$ & $\begin{array}{c}\text { No. of } \\
\text { records }\end{array}$ \\
\hline Milk yield $(\mathrm{kg} / \mathrm{d})$ & 30.7 & 8.98 & $11.20-52.10$ & 128,112 & $2,514,762$ \\
Fat $(\%)$ & 3.56 & 0.78 & $1.77-5.46$ & 128,003 & $2,466,055$ \\
Protein $(\%)$ & 3.27 & 0.34 & $2.59-4.20$ & 127,977 & $2,475,092$ \\
Fat yield $(\mathrm{kg} / \mathrm{d})$ & 1.07 & 0.34 & $0.39-2.04$ & 128,003 & $2,466,055$ \\
Protein yield $(\mathrm{kg} / \mathrm{d})$ & 0.99 & 0.26 & $0.39-1.60$ & 127,977 & $2,475,092$ \\
SCC $(\times 1,000 / \mathrm{mL})$ & 275 & 549.71 & $8-2,979$ & 127,831 & $2,473,022$ \\
\hline
\end{tabular}

netic values and (co)variance components within the Gibbs sampling. Details of the calculation procedure for the model comparison statistics can be found in López-Romero et al. (2003). The best model is the one with the minimum value of $\mathrm{D}$ and the maximum value of LMD. Differences between LMD values for 2 models provide an estimate of the natural logarithm of the Bayes factor (see, for example, Kass, 1993), which provides evidence of the superiority of one model over the other in a Bayesian framework.

\section{RESULTS}

Table 1 presents summary statistics of the phenotypic data used in the subsequent analyses. The observed means for the analyzed traits were generally coincident with results from other Holstein populations (Bohmanova et al., 2007; Aguilar et al., 2009; Hammami et al., 2013; Smith et al., 2013), indicating a similarly high level of selection for production traits in this population.

Table 2 shows percentiles of the distribution of daily average and maximum temperatures during the days when data were recorded. If we assume that the heat stress threshold for cattle is $26^{\circ} \mathrm{C}$ (Kadzere et al., 2002), then around $30 \%$ of the records used in the analyses would have been collected under heat stress conditions. Therefore, the estimation of heat stress effects should be possible in this population. Maximum values of daily temperatures were 34.0 and $42.0^{\circ} \mathrm{C}$ for $\mathrm{T}_{\mathrm{AVE}}$ and $\mathrm{T}_{\mathrm{MAX}}$, respectively. Taking values of maximum temperatures and minimum relative humidity of 25 to $30 \%$ and the NRC (1971) formula to compute THI, average and maximum THI would be around 80 and 88 , respectively. These values are in the range of maximum
THI found in other studies dealing with heat stress in Holstein cattle in the United States (Bohmanova et al., 2007) and in Italy (Bernabucci et al., 2014).

\section{Reaction Norm of Production to Temperature Increase: Population Level}

Figure 1 shows raw and adjusted (for environmental and animal effects in Equation [1]) production and SCS averages at successive temperature degrees together with the SP and LP fits. This figure allows visualizing the actual pattern of the data and the fit provided by the 2 types of models analyzed. Adjustment for environmental effects had a large effect on the observed pattern in the data, particularly for milk and fat yield. Adjusted milk production showed a cold stress region as well as a heat stress area, whereas fat yield tended to decrease in all the range of temperatures. These patterns differ from the expected broken line pattern assumed in the SP models. For protein yield, thermoneutral and decline zones were observed, although the change between the 2 zones was not as abrupt as in the SP models. For SCS, a dispersed pattern was observed.

Table 3 shows the estimated tolerance thresholds and slopes for the SP models and the maxima and derivatives at the SP threshold for the LP functions in Figure 1. Comfort thresholds for $\mathrm{T}_{\mathrm{AVE}}$ were $29.2^{\circ} \mathrm{C}$ (corresponding to a value of 73 for THI at a $25 \%$ relative humidity) for milk yield, $15^{\circ} \mathrm{C}$ ( $\left.59 \mathrm{THI}\right)$ for fat yield and SCS, and $18.1^{\circ} \mathrm{C}(62 \mathrm{THI})$ for protein yield. Thresholds for $\mathrm{T}_{\mathrm{MAX}}$ for fat and protein yields were slightly higher (from 1 to $3^{\circ} \mathrm{C}$ ), as expected. The threshold for $\mathrm{T}_{\mathrm{MAX}}$ for milk was found at $15^{\circ} \mathrm{C}$ but with a positive slope. This threshold seems to correspond to a change of slope from the cold to the comfort temperatures (see Figure

Table 2. Percentiles of the distribution of daily average $\left(\mathrm{T}_{\mathrm{AVE}}\right)$ and maximum $\left(\mathrm{T}_{\mathrm{MAX}}\right)$ temperatures associated with the test-day records

\begin{tabular}{|c|c|c|c|c|c|c|c|c|c|c|c|}
\hline \multirow{2}{*}{$\begin{array}{l}\text { Temperature } \\
\left({ }^{\circ} \mathrm{C}\right)\end{array}$} & \multicolumn{11}{|c|}{ Percentile } \\
\hline & 0 & 10 & 20 & 30 & 40 & 50 & 60 & 70 & 80 & 90 & 100 \\
\hline $\mathrm{T}_{\mathrm{AVE}}$ & -1 & 8 & 10 & 12 & 14 & 16 & 18 & 21 & 24 & 26 & 34 \\
\hline $\mathrm{T}_{\mathrm{MAX}}$ & 2 & 12 & 15 & 17 & 19 & 22 & 24 & 28 & 31 & 35 & 42 \\
\hline
\end{tabular}



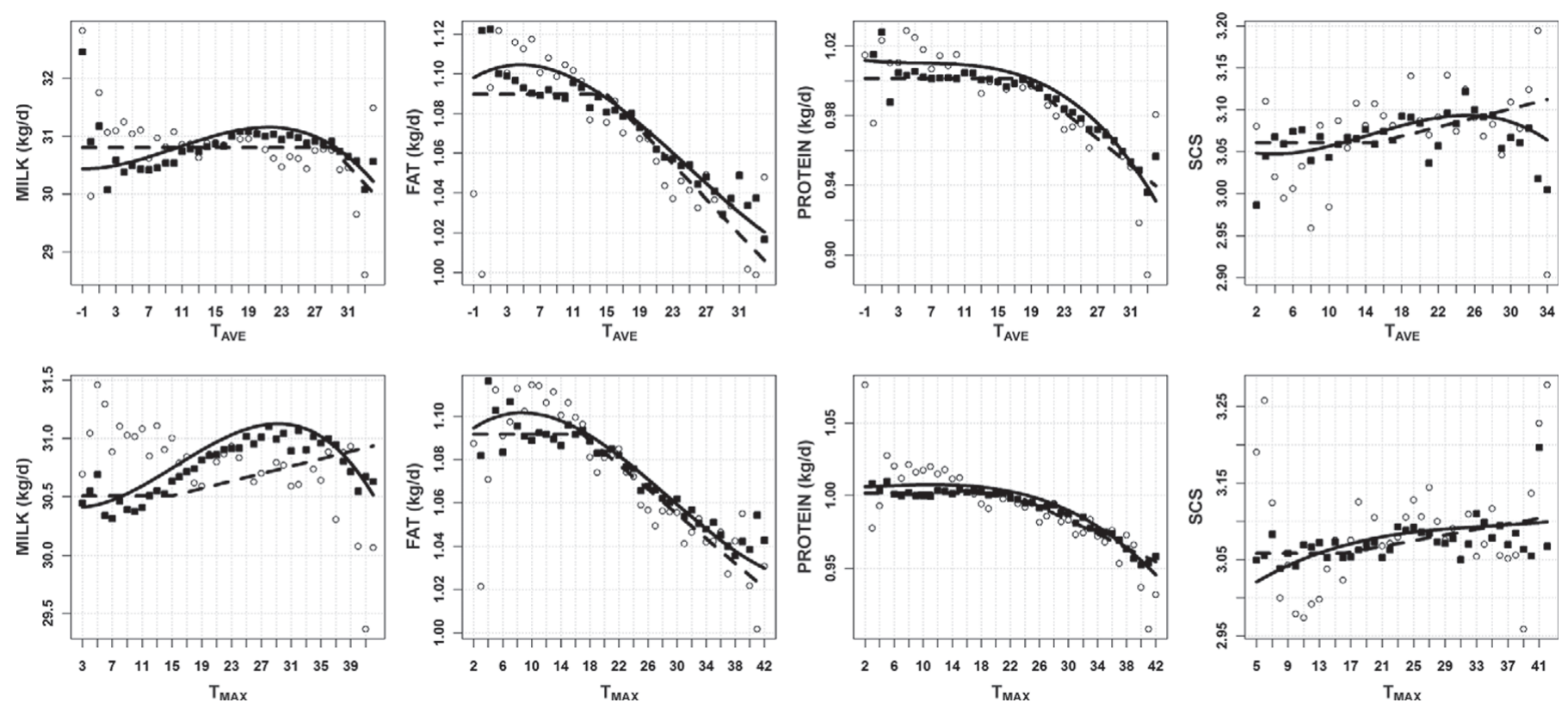

Figure 1. Average of raw (empty circles) and adjusted by environmental and animal effects (filled squares) records by degree of average $\left(\mathrm{T}_{\mathrm{AVE}}\right)$ and maximum $\left(\mathrm{T}_{\mathrm{MAX}}\right)$ daily temperature and spline (discontinuous line) and polynomial (solid line) fits for production traits and SCS.

1). Starting the algorithm search at the hot or cold temperatures extremes provided the same threshold in this case. Maxima from LP models were much lower than SP thresholds and do not seem to be good proxies for comfort thresholds. For all traits, the estimated slope from SP models was larger than the first derivative of the LP functions at the SP threshold (Table 3). This was expected from the gradually steeper decrease with temperature provided by polynomial functions versus the single slope provided by SP models. For $\mathrm{T}_{\mathrm{AVE}}$, milk production showed a decline of -157.4 and $-87.6 \mathrm{~g} / \mathrm{d}$ per degree Celsius above the threshold of thermotolerance for SP and LP models, respectively. For $\mathrm{T}_{\mathrm{MAX}}$, no relevant figures are found given the fact that the comfort threshold estimated by the SP model $\left(15.0^{\circ} \mathrm{C}\right)$ was too low. Decreases of around -4.4 and $-3.8 \mathrm{~g} / \mathrm{d}$ per degree Celsius of $T_{A V E}$ were found for fat and protein yields, respectively, with the SP models. For $\mathrm{T}_{\mathrm{MAX}}$, the decay estimated for these traits was smaller: -2.8 and $-2.3 \mathrm{~g} / \mathrm{d}$ per degree Celsius, for fat and protein yield, respectively. For SCS, slopes of $2.7 \times 10^{-3}$ and $3.2 \times$ $10^{-3}$ (score units $/{ }^{\circ} \mathrm{C}$ ) were estimated for $\mathrm{T}_{\mathrm{AVE}}$ for $\mathrm{SP}$ and LP, respectively. For $\mathrm{T}_{\mathrm{MAX}}$, a slope of $1.8 \times 10^{-3}$ (score units $/{ }^{\circ} \mathrm{C}$ ) was estimated from the SP model. No maximum/minimum of the polynomial was found for SCS in the range of temperatures under consideration. The implication of the sharper slopes found for the SP models is that this model is likely to estimate larger losses from heat stress compared with those from the LP models. This is so because at the threshold $T_{o}$ the area under the SP curve tends to be smaller than the one under the LP curve (see Figure 1).

To explore the rate of decay in production (increase for SCS) in the LP models, we obtained the value of the first derivative at temperatures different from the SP threshold. Table 4 shows the values of the derivative of the polynomial functions in a range of temperatures above $20^{\circ} \mathrm{C}$ for $\mathrm{T}_{\mathrm{AVE}}$ and $25^{\circ} \mathrm{C}$ for $\mathrm{T}_{\mathrm{MAX}}$. Maximum decays in production were found for $\mathrm{T}_{\mathrm{AVE}},-169.9 \mathrm{~g} / \mathrm{d}$ for milk yield at $34^{\circ} \mathrm{C},-3.83 \mathrm{~g} / \mathrm{d}$ for fat yield at $25^{\circ} \mathrm{C}$, and -8.16 for protein yield at $34^{\circ} \mathrm{C}$. For SCS, the largest increase in SCS across the range of temperatures in this table was found to be $2.4 \times 10^{-3}$ (score units $/{ }^{\circ} \mathrm{C}$ ) at $20^{\circ} \mathrm{C}$. At higher temperatures, the rate of increase was lower and even negative. This result was unexpected and it might indicate that temperature could be a factor affecting SCS only in the presence of mastitis.

Goodness of fit of the models used in this part of the study was compared using the DIC values (Table 5). Although differences in DIC across models were not very large, a consistent improvement in this criterion was found for all traits when comparing SP versus LP models and $\mathrm{T}_{\mathrm{MAX}}$ versus $\mathrm{T}_{\mathrm{AVE}}$; overall, the LP model (a cubic polynomial) with $\mathrm{T}_{\mathrm{AVE}}$ as measure of heat load was the best-fit model.

\section{Reaction Norm of Production to Temperature Increase: Individual Genetic Components}

Figure 2 shows the EBV for the 10 top-ranked, 10 bottom-ranked and 5 randomly sampled animals for 
each trait at different degrees of average daily temperature and at 50 DIM for the DIM3TEM3 and DIM3DUMMY models. The criterion to rank the animals was the posterior mean of the additive genetic intercept coefficient for each trait, which can be associated with the overall genetic potential for production or SCS. We chose to show DIM 50 figures to look at results around the peak of lactation, when cows should be under the highest metabolic heat production. Patterns for other models, for $\mathrm{T}_{\mathrm{MAX}}$, and for other DIM (not shown) showed similar trends. The EBV for production traits along the studied temperature range tended to decline at high temperatures for the top-ranked animals. For the bottom-ranked animals, flat or slightly increasing trends were observed. For SCS, animals with the highest genetic level to produce somatic cells in milk (undesirable) showed larger-than-average counts with high temperatures. The opposite was found for animals with the lowest genetic potential (desirable) for SCS. Animals with average overall genetic merit for the studied traits did not change their EBV when temperature increased. Breeding values estimated under the DIM3DUMMY model mimicked the DIM3TEM3 EBV pattern after the pre-established threshold. For fat and protein yields, for which the comfort thresholds were set at lower temperatures, larger slopes of decay were estimated for the DIM3DUMMY model than for the counterpart DIM3TEM3. This resulted in larger reranking of animals from cold or medium to hot temperatures. In agreement with the antagonistic relationship between level and tolerance to heat stress seen in EBV in Figure 2, estimated correlations between intercept and slope additive genetic coefficients were also antagonistic. Estimated genetic correlations between the intercept and the linear coefficient for TEM_ models or slope for_DUMMY models ranged from -0.21 for protein yield in the DIM3TEM3 model to -0.34 for fat yield in the DUMMY model.

Heritability estimates along increasing temperatures are presented in Figure 3. Estimated heritability values ranged between 0.10 and 0.35 for production traits and between 0.08 and 0.22 for SCS, depending on the stage of lactation, model, and temperature. Stage of lactation was responsible for the largest changes in heritability estimates, with higher estimates for later lactation stages. Heritability estimates tended to show a slight decrease as temperature increased for DIM3TEM_ models but almost flat curves were observed for TEM_ models. Cubic polynomials tended to show a steep increase in heritability estimates at the extremes of the studied range of the independent variable (temperature in this case), probably due to artifacts of polynomial functions. Overall, decreases in heritability with temperature were relatively small (up 
Table 4. Posterior means and $95 \%$ high posterior density intervals (in parentheses) of the derivatives of the Legendre polynomial models at several daily average $\left(\mathrm{T}_{\mathrm{AVE}}\right)$ and maximum $\left(\mathrm{T}_{\mathrm{MAX}}\right)$ temperatures for production traits and $\mathrm{SCS}$

\begin{tabular}{lcccc}
\hline & & Yield & & \\
\cline { 2 - 5 } & $\begin{array}{c}\text { Milk } \\
\text { Item }\end{array}$ & $\begin{array}{c}\text { Fat } \\
\left(\mathrm{g} / \mathrm{d} \text { per }{ }^{\circ} \mathrm{C}\right)\end{array}$ & $\begin{array}{c}\text { Protein }) \\
\left(\mathrm{g} / \mathrm{d} \text { per }{ }^{\circ} \mathrm{C}\right)\end{array}$ & \\
\hline $\mathrm{T}_{\text {AVE }}\left({ }^{\circ} \mathrm{C}\right)$ & & & & \\
20 & $11.56(9.73$ to 13.43$)$ & $-3.61(-3.69$ to -3.52$)$ & $-2.17(-2.23$ to -2.12$)$ & $2.40(1.88$ to 2.91$)$ \\
25 & $-35.83(-38.83$ to -32.86$)$ & $-3.83(-3.96$ to -3.69$)$ & $-3.86(-3.96$ to -3.77$)$ & $0.15(-0.69$ to 0.97$)$ \\
30 & $-102.57(-110.31$ to -93.15$)$ & $-3.57(-3.93$ to -3.14$)$ & $-6.05(-6.30$ to -5.76$)$ & $-3.51(-5.67$ to -0.90$)$ \\
34 & $-169.90(-184.32$ to -154.52$)$ & $-3.04(-3.70$ to -2.33$)$ & $-8.16(-8.62$ to -7.68$)$ & $-7.46(-11.45$ to -3.16$)$ \\
$\mathrm{T}_{\text {MAX }}\left({ }^{\circ} \mathrm{C}\right)$ & & & & \\
25 & $20.71(19.09$ to 22.50$)$ & $-2.80(-2.87$ to -2.72$)$ & $-1.46(-1.51$ to -1.40$)$ & $1.23(0.78$ to 1.73$)$ \\
30 & $-4.40(-5.96$ to -2.77$)$ & $-2.89(-2.96$ to -2.82$)$ & $-2.34(-2.39$ to -2.29$)$ & $0.78(0.35$ to 1.24$)$ \\
35 & $-40.01(-43.76$ to -36.05$)$ & $-2.62(-2.80$ to -2.44$)$ & $-3.40(-3.52$ to -3.28$)$ & $0.64(-0.41$ to 1.74$)$ \\
40 & $-86.12(-94.09$ to -77.33$)$ & $-2.00(-2.36$ to -1.59$)$ & $-4.65(-4.90$ to -4.37$)$ & $0.80(-1.43$ to 3.25$)$ \\
\hline
\end{tabular}

to 0.08 , except for the extremes in the DIM3TEM3 model).

Figure 4 shows the posterior means of the genetic correlation between successive temperature degrees for $\mathrm{T}_{\mathrm{AVE}}$ for milk and protein production and SCS under models including Legendre polynomials on temperature only (TEM_) and DIM3TEM_ models at 50 DIM. Fat yield results are not shown because the pattern was very close to the protein pattern. Large values of this correlation are interpreted as an indication of no genotype by environment $(\mathbf{G} \times \mathbf{E})$ interaction or tolerance to heat stress in the sense that the genetic potential of an individual for the trait is similar across the range of temperatures. A wide range of estimates of the genetic correlation between extreme temperatures $(-1$ and $34^{\circ} \mathrm{C}$ for $\mathrm{T}_{\mathrm{AVE}}$ ) was observed across models for the same trait. These values ranged from 0.79 to $0.88,0.24$ to $0.86,0.26$ to 0.86 , and 0.30 to 0.86 for milk, fat, and protein yield and SCS, respectively. Despite the large variation, milk yield always showed larger estimated correlations than the other traits, indicating that, in our case, this trait is less susceptible to changes in temperature than the other traits. The largest values of the genetic correlation were always found for models fitting a quadratic polynomial for temperatures (TEM2 and DIM3TEM2). This might be due to polynomial artifacts in the sense that low-degree polynomials do not allow fitting complex patterns or, on the other hand, to polynomials of higher degree showing abnormal behavior at the extremes values of the independent variable.

To illustrate the effect of the lactation stage on the tolerance to heat stress, Table 6 shows values of
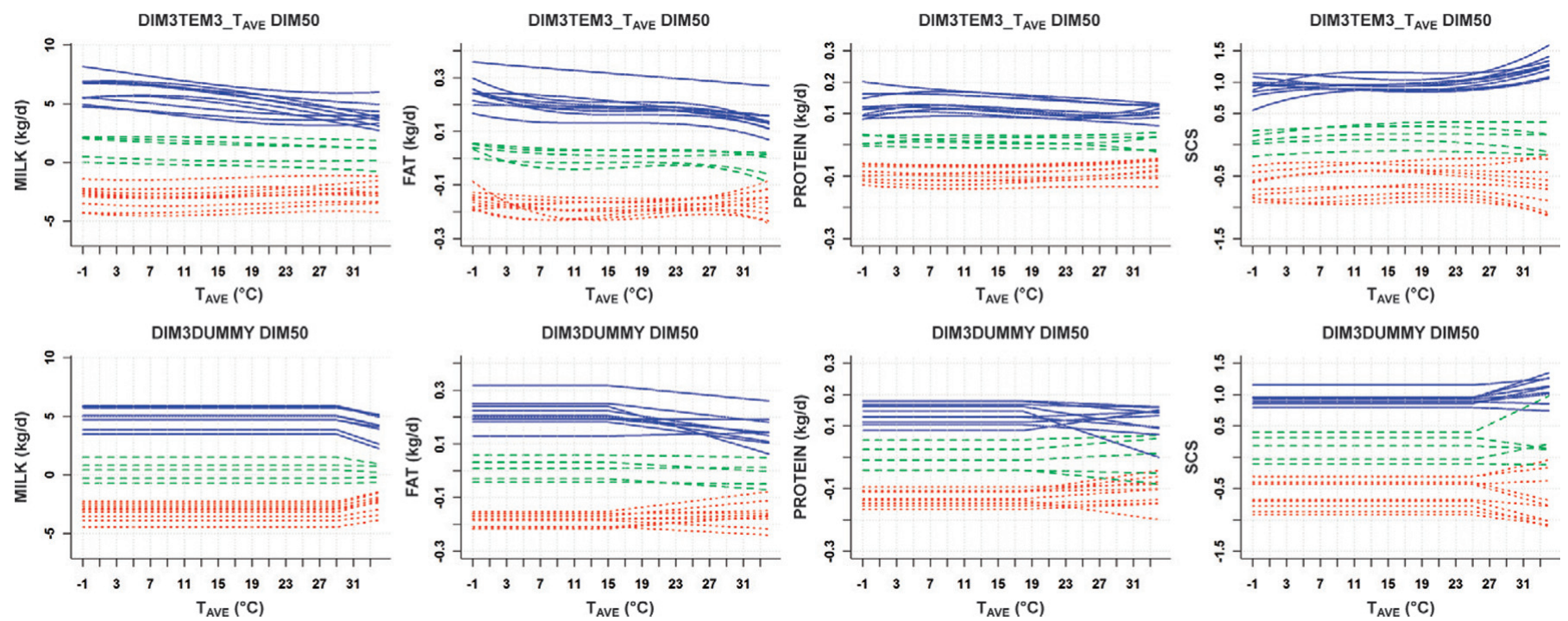

Figure 2. Estimated breeding values for 10 top (solid line), 10 bottom (dotted line), and 5 randomly sampled (dashed line) animals at different degrees of average daily temperature $\left(\mathrm{T}_{\mathrm{AVE}}\right)$ at 50 DIM for a model with random cubic polynomial for DIM and temperature (DIM3TEM3) and with a dummy variable for temperatures (DIM3DUMMY) for production traits and SCS. Color version available in the online PDF. 

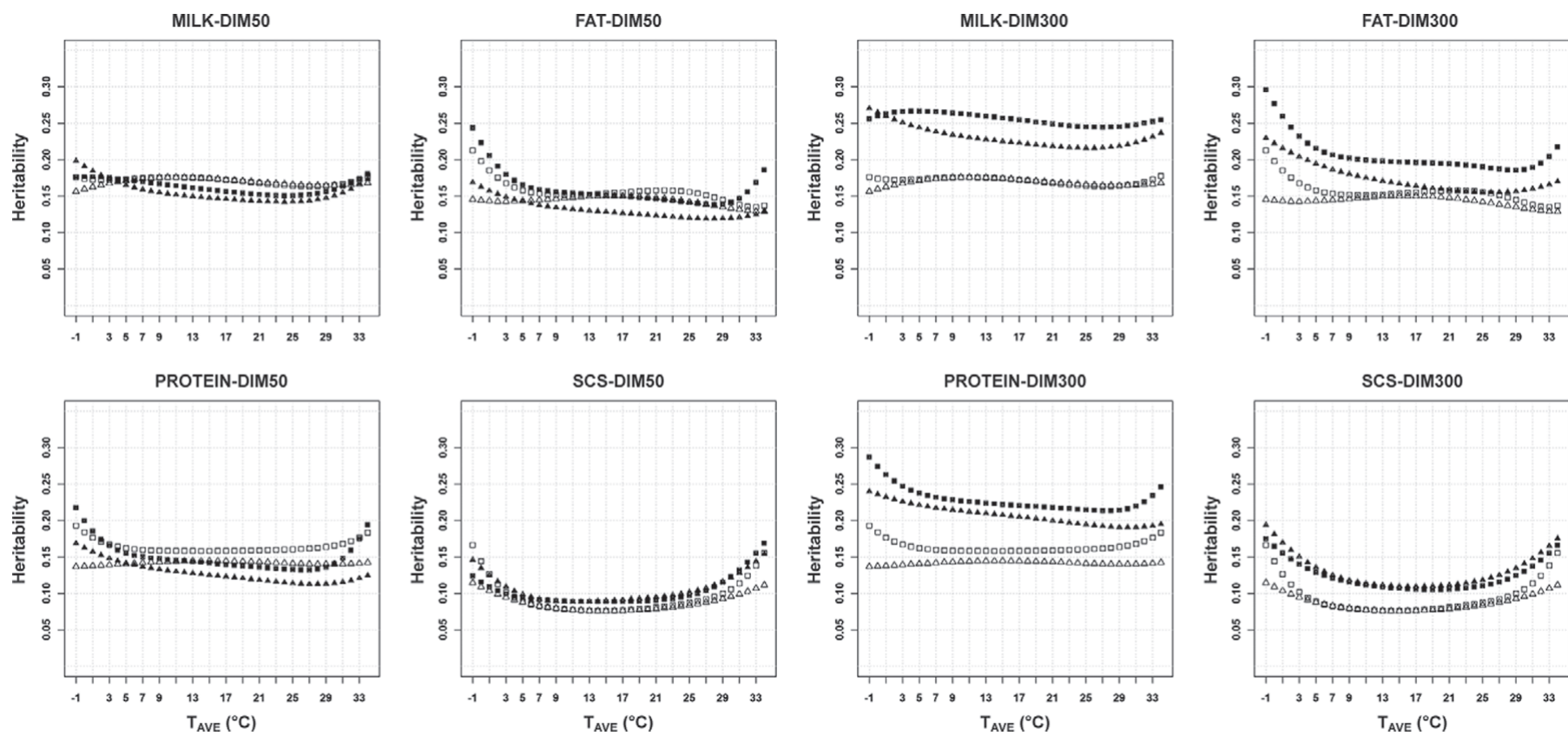

Figure 3. Posterior means of heritability for successive degrees of average daily temperature $\left(\mathrm{T}_{\mathrm{AVE}}\right)$ and for DIM 50 and 300 under models including additive genetic quadratic (TEM2; empty triangles) and cubic (TEM3; empty squares) regressions on $\mathrm{T}_{\mathrm{AVE}}$ and under models including an additive genetic cubic regression on DIM and quadratic (DIM3TEM2; filled triangles) and cubic (DIM3TEM3; filled squares) polynomials on $\mathrm{T}_{\mathrm{AVE}}$ for production traits and SCS.

posterior means for correlations between the genetic values at extreme temperatures for $\mathrm{T}_{\mathrm{AVE}}$ for all traits and models at different DIM values. Estimated genetic correlations for 2 pairs of temperatures are shown in the table $\left(\mathbf{P} \mathbf{1}=0\right.$ vs. $33^{\circ} \mathrm{C}$ and $\mathbf{P} \mathbf{2}=10$ vs. $\left.30^{\circ} \mathrm{C}\right)$ for $\mathrm{T}_{\mathrm{AVE}}$. In the first case, correlations between cold and hot temperatures are provided. The extreme temperatures $\left(-1\right.$ and $\left.34^{\circ} \mathrm{C}\right)$ were not considered to avoid as much as possible the end of range effect on estimates in polynomial fits. In the second case (P2), correlations show changes in ranking between the comfort zone and hot temperatures. Estimated correlations were always larger for P2 than for P1. Estimated correlations were lowest around lactation peak (50 DIM) and highest at the end of lactation (300 DIM) for production traits. For SCS, the smallest correlations were found for mid lactation. Overall, estimated genetic correlations ranged from 0.40 (for fat yield, under the DIM3TEM3 model at 50 DIM) to 0.92 (for milk yield, under the TEM3 model) for P1 and from 0.85 (for SCS, under the DIM3TEM3 model at 90 DIM) to 0.96 (for milk yield under the TEM3 and DIM3TEM3 models at DIM 150).

Figure 5 shows the eigenfunctions and percentage of variability in the patterns of response to increasing temperature associated with each new variable resulting from the eigendecomposition of the matrix of (co) variances between additive genetic random regression coefficients for the TEM3 model. Through this decomposition, the variability in shapes of response of yields and SCS to temperature, described by the random regression coefficients, is decomposed into independent parts. These parts are associated with new variables obtained as linear combinations of the original coefficients. In this case, where the original variables are

Table 5. Deviance information criterion (DIC) values for splines and polynomial models for production traits and SCS with average $\left(\mathrm{T}_{\mathrm{AVE}}\right)$ and maximum $\left(\mathrm{T}_{\mathrm{MAX}}\right)$ daily temperatures ${ }^{1}$

\begin{tabular}{lrrrrr}
\hline & \multicolumn{3}{c}{$\mathrm{T}_{\text {AVE }}$} & & \multicolumn{2}{c}{$\mathrm{T}_{\text {MAX }}$} \\
\cline { 2 - 3 } \cline { 5 - 6 } Item & Spline & Polynomial & & \multicolumn{1}{c}{ Spline } & \multicolumn{1}{c}{ Polynomial } \\
\hline Milk & $6,570,261.7$ & $\mathbf{6 , 5 6 9 , 0 3 2 . 3}$ & & $6,569,773.7$ & $6,569,053.0$ \\
Fat & $-798,892.8$ & $\mathbf{- 7 9 9 , 0 7 9 . 3}$ & & $-798,397.4$ & $-798,317.3$ \\
Protein & $-1,709,251.6$ & $\mathbf{- 1 , 7 0 9 , 2 8 9 . 1}$ & & $-1,708,358.6$ & $-1,708,476.4$ \\
SCS & $3,505,640.7$ & $\mathbf{3 , 5 0 5 , 5 8 6 . 9}$ & & $3,505,615.3$ & $3,505,594.0$ \\
\hline
\end{tabular}

${ }^{1}$ Minimum (best) values for DIC are in boldface. 

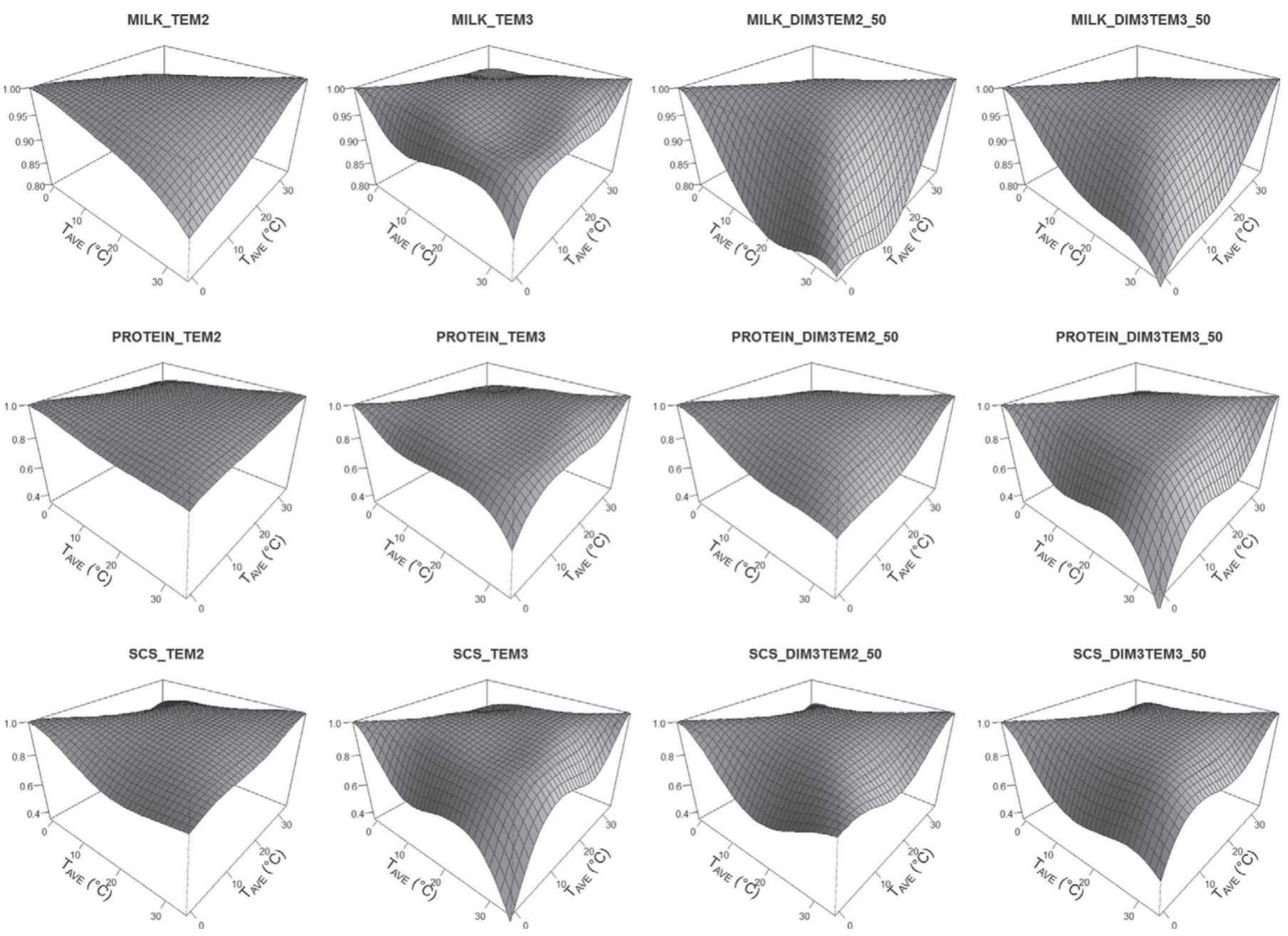

Figure 4. Posterior means of the genetic correlation between production and SCS at different daily average temperatures ( $\left.\mathrm{T}_{\mathrm{AVE}}\right)$ under models including additive genetic quadratic (TEM2) and cubic (TEM3) regressions on $\mathrm{T}_{\mathrm{AVE}}$ and under models including an additive genetic cubic regression on DIM and quadratic (DIM3TEM2) and cubic (DIM3TEM3) polynomials on $\mathrm{T}_{\mathrm{AVE}}$ for milk and protein yield and SCS.

regression coefficients, each new component has an associated eigenfunction that describes the behavior of the new variable along the regressor (in our case, temperature). By construction, the first new variable will explain the largest possible amount of the original variability. For all traits, the first eigenfunction was associated with an almost constant level of production across the range of temperatures, corresponding to a large weight on the intercept coefficient (data not shown). This variable accounted for $91,76,79$, and $64 \%$ for milk, fat, and protein yield and SCS, respectively. This means that, especially for milk yield, most of the variability of the shape of response to increasing temperatures is associated with the genetic potential for production of each individual. For fat and protein yield and SCS, the second eigenfunction explained 15, 11 , and $24 \%$, respectively. This new variable showed a flat response between 9 and $25^{\circ} \mathrm{C}$ for $\mathrm{T}_{\mathrm{AVE}}$, which might coincide with a thermoneutral zone, and decreasing or increasing values outside that range of temperatures.

Finally, Figure 6 shows the model comparison criteria (LMD) as a goodness-of-fit criterion and D for predictive ability for all traits and models analyzed. The worst models were DUMMY and TEM2 for all traits and the 2 criteria (except for protein yield and the D criterion, for which DIM3TEM2 was slightly worse than TEM2). The pattern of values for both criteria across models differed between fat and protein yield versus milk yield and SCS. For milk and SCS, DIM3_ models showed better goodness of fit (LMD criterion) and predictive ability (D criterion) than models including only temperature (DUMMY, TEM2, and TEM3). For milk and SCS, all models including random regressions on DIM showed similar values for the comparison criteria. On the other hand, for fat and protein yield, the improvement came from increasing 
Table 6. Posterior means for correlations between 2 pairs of temperatures $\left(\mathrm{P} 1=0\right.$ vs. $33^{\circ} \mathrm{C}$ and $\mathrm{P} 2=10$ vs. $\left.30^{\circ} \mathrm{C}\right)^{1}$ and of daily average temperature $\left(\mathrm{T}_{\mathrm{AVE}}\right)$ for production traits and SCS under models including additive genetic quadratic (TEM2) and cubic (TEM3) regressions only on $\mathrm{T}_{\mathrm{AVE}}$ and under models including an additive genetic cubic regression on DIM and quadratic (DIM3TEM2) and cubic (DIM3TEM3) polynomials on $\mathrm{T}_{\mathrm{AVE}}$ for DIM

\begin{tabular}{|c|c|c|c|c|c|c|c|c|c|}
\hline \multirow[b]{3}{*}{ Model } & \multirow[b]{3}{*}{ DIM } & \multicolumn{6}{|c|}{ Yield } & & \\
\hline & & \multicolumn{2}{|c|}{ Milk } & \multicolumn{2}{|c|}{ Fat } & \multicolumn{2}{|c|}{ Protein } & \multicolumn{2}{|c|}{ SCS } \\
\hline & & $\mathrm{P} 1$ & $\mathrm{P} 2$ & $\mathrm{P} 1$ & $\mathrm{P} 2$ & $\mathrm{P} 1$ & $\mathrm{P} 2$ & $\mathrm{P} 1$ & $\mathrm{P} 2$ \\
\hline TEM2 & - & 0.90 & 0.95 & 0.80 & 0.94 & 0.87 & 0.95 & 0.84 & 0.93 \\
\hline DIM3TEM2 & 20 & 0.84 & 0.90 & 0.84 & 0.93 & 0.78 & 0.89 & 0.86 & 0.92 \\
\hline DIM3TEM2 & 50 & 0.82 & 0.89 & 0.81 & 0.91 & 0.74 & 0.86 & 0.82 & 0.88 \\
\hline DIM3TEM2 & 90 & 0.86 & 0.92 & 0.81 & 0.91 & 0.77 & 0.88 & 0.79 & 0.85 \\
\hline DIM3TEM2 & 150 & 0.89 & 0.94 & 0.84 & 0.92 & 0.82 & 0.91 & 0.81 & 0.85 \\
\hline DIM3TEM2 & 300 & 0.88 & 0.92 & 0.87 & 0.93 & 0.86 & 0.93 & 0.86 & 0.90 \\
\hline TEM3 & - & 0.92 & 0.96 & 0.67 & 0.95 & 0.74 & 0.92 & 0.46 & 0.92 \\
\hline DIM3TEM3 & 20 & 0.83 & 0.92 & 0.48 & 0.91 & 0.46 & 0.88 & 0.75 & 0.94 \\
\hline DIM3TEM3 & 50 & 0.82 & 0.92 & 0.40 & 0.88 & 0.41 & 0.86 & 0.66 & 0.91 \\
\hline DIM3TEM3 & 90 & 0.85 & 0.94 & 0.44 & 0.89 & 0.49 & 0.89 & 0.60 & 0.88 \\
\hline DIM3TEM3 & 150 & 0.88 & 0.96 & 0.50 & 0.91 & 0.58 & 0.92 & 0.61 & 0.88 \\
\hline DIM3TEM3 & 300 & 0.86 & 0.95 & 0.50 & 0.91 & 0.64 & 0.93 & 0.71 & 0.92 \\
\hline
\end{tabular}

${ }^{1}$ Posterior SD largest values were 0.09 for P1 and 0.02 for P2.

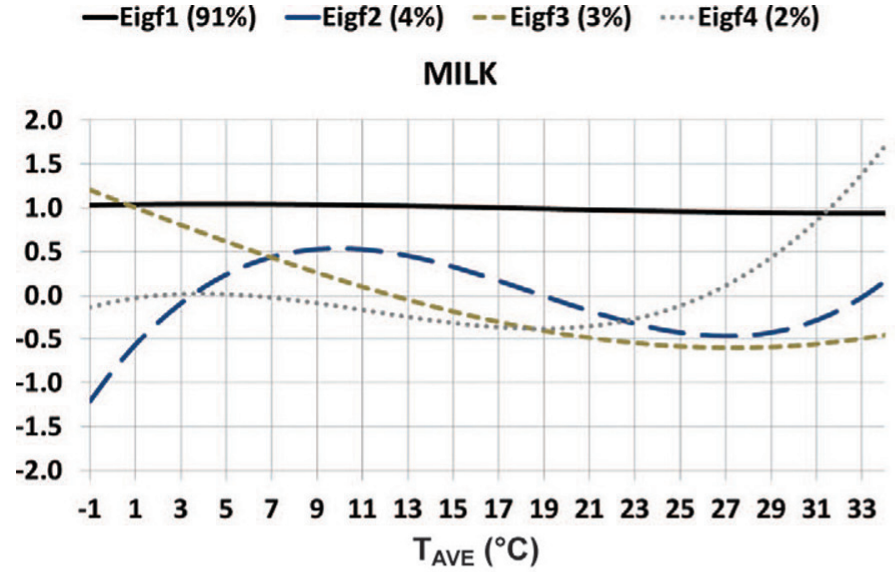

一Eigf1 (76\%) 一Eigf2 (15\%) --Eigf3 (6\%) …Eigf4 (3\%)

FAT

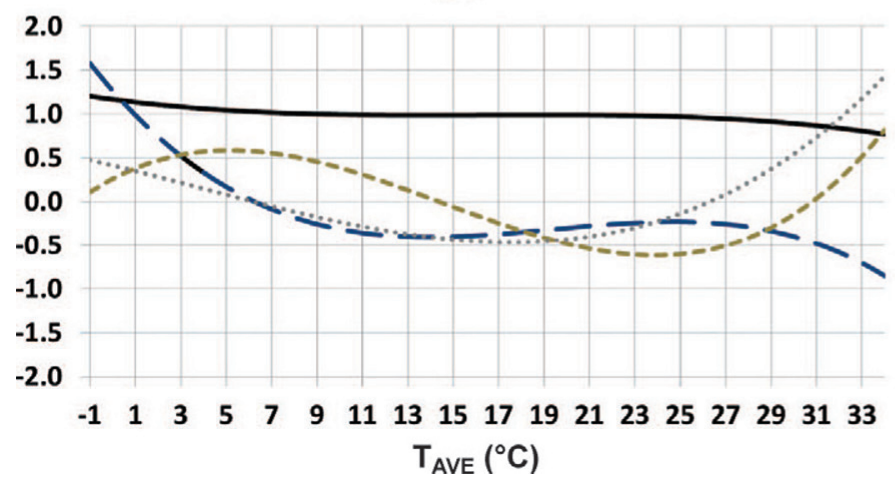

一Eigf1 (79\%) -Eigf2 (11\%) --Eigf3 (6\%) …Eigf4 (4\%) PROTEIN

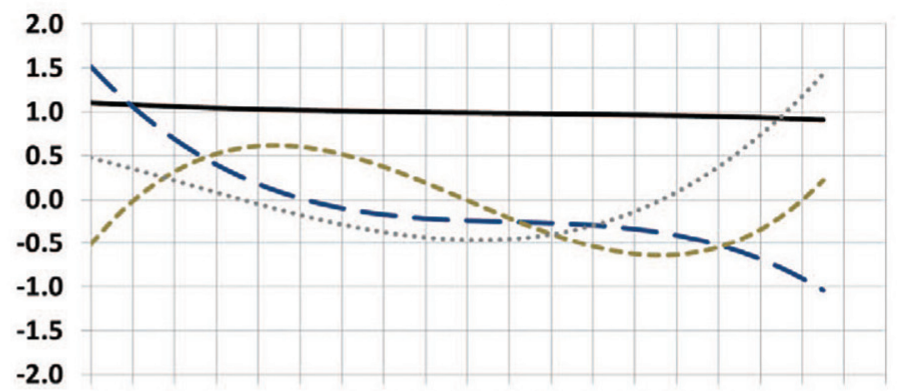

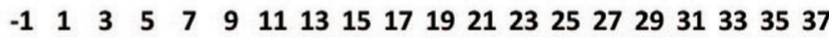
$\mathrm{T}_{\mathrm{AVE}}\left({ }^{\circ} \mathrm{C}\right)$

\section{一Eigf1 (64\%) -Eigf2 (24\%) --Eigf3 (7\%) - - Eigf4 (5\%)} SCS

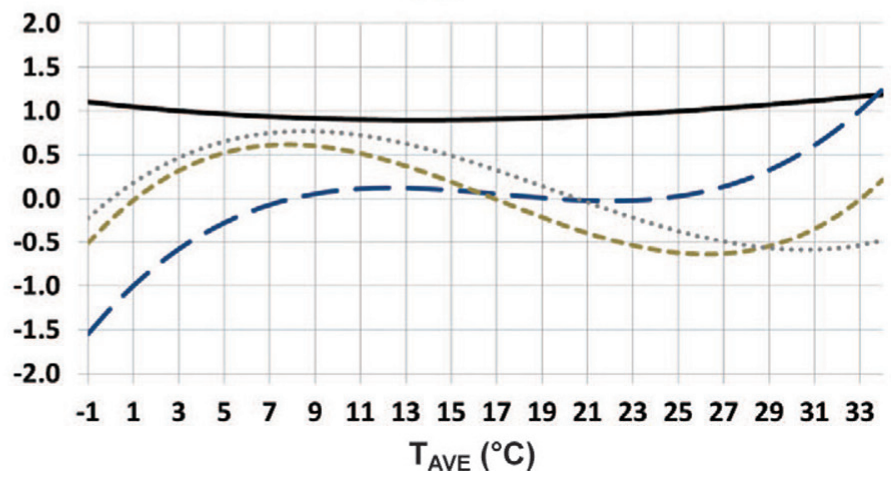

Figure 5. Eigenfunctions (Eigf) and percentage of variability explained by the new canonical variables (top in parentheses) obtained from the matrix of (co)variance components of the additive genetic regression coefficients for model adjusting a cubic polynomial on temperatures (TEM3 model). $\mathrm{T}_{\mathrm{AVE}}=$ average daily temperature. Color version available in the online PDF. 
the polynomial degree fitted to temperature from quadratic (TEM2 and DIM3TEM2) to cubic (TEM3 and DIM3TEM3). Interestingly, the DIM3DUMMY model showed a better behavior than the TEM2 and TEM3 models and was close to the DIM3TEM3 model for both criteria. For protein yield, the preferred model according to both criteria was TEM3. However, for fat, DIM3TEM3 was the best model according to the goodness-of-fit criterion and TEM3 for the predictive ability. Therefore, from the model comparison criteria, it seems that models including a cubic polynomial to fit temperature effects are more appropriate than models fitting a quadratic polynomial for fat and protein yield.

\section{DISCUSSION}

Modeling and quantifying the effect of temperature on milk production phenotypically has been the subject of many previous studies. Two features of this relationship, the threshold of comfort and the decay of production after the threshold, have been used to characterize it. The value for the threshold has been established around $26^{\circ} \mathrm{C}$ (see, for example, review by Kadzere et al., 2002) and 72 units of THI (NRC, 1971). According to Collier et al. (2012), current cooling standards use a THI threshold of 72 . This threshold coincides with estimates in Ravagnolo and Misztal (2000) and Bernabucci et al. (2014) using test-day information from US and Italian Holsteins, respectively. However, Zimbelman et al. (2009) reevaluated the validity of the THI 72 threshold and established a more realistic value of 68 for the increasingly productive Holstein cow. This is in line with estimates of Hammami et al. (2013) and Brügemann et al. (2011), who found thresholds close to this figure in Central European Holsteins. Segnalini et al. (2013) established a continuous classification for heat stress effect as THI $<68$ (no risk), $68 \leq$ THI $<72$ (mild discomfort), $72 \leq$ THI $<75$ (discomfort), $75 \leq$ THI $<79$ (alert), $79 \leq$ THI $<84$ (danger), and THI $\geq 84$ (emergency). In our study, heat stress threshold estimates from the SP model were high for milk $\left(29^{\circ} \mathrm{C}\right.$ for $\mathrm{T}_{\mathrm{AVE}}$ or 74 for THI) and substantially lower for fat and protein yield and for SCS (around 15 to $18^{\circ} \mathrm{C}$ for $\mathrm{T}_{\mathrm{AVE}}$ or 17 to $22^{\circ} \mathrm{C}$ for $\mathrm{T}_{\mathrm{MAX}}$ and 61 to 66 for THI, using maximum temperature and minimum relative humidity). Comfort threshold estimates for fat and protein yields were unexpectedly low. Estimated thresholds for milk yield and milk components disagree with previous studies that have found similar thresholds for both types of traits in cattle (Ravagnolo and Misztal, 2000; Bernabucci et al., 2014) and sheep (Finocchiaro et al., 2005). In our study, the pattern of response of milk components to increasing heat loads did not show a clear threshold followed by a smooth decline. Moreover, the observed pattern is a constantly decreasing and markedly jagged profile (as shown in Figure 1), which might make it difficult for the searching algorithm to detect the true change point. We used different starting points to ensure that all led to the same change point, but this was not always the case, indicating difficulties in finding a unique change point. Other authors have also found a pattern of steady decrease in fat or protein yield, or both, with increasing heat loads (Ravagnolo and Misztal, 2000; Brügemann et al., 2012; Hammami et al., 2013). Moreover, difficulties in computing the threshold for milk components have been reported by Brügemann et al. (2012) and Hammami et al. (2013). For SCS, patterns of response were more disperse and as of yet unidentified factors might have to be taken into account to obtain accurate estimates of the effect of heat stress on this trait.

The previously mentioned results question the use of the broken-line (SP in this study) model that assumes one comfort zone up to a threshold and then a steady decline or increase to describe heat stress effects on production and SCS. The observed patterns for production traits versus heat load did not seem to follow the broken-line model in all cases. Milk yield showed a cold as well as a heat stress region, fat yield tended to decrease across the whole range of temperatures with different slopes, and SCS showed a quite erratic pattern with no clear sign of one threshold. In fact, the estimate of the comfort threshold was also too low for milk yield and $\mathrm{T}_{\mathrm{MAX}}\left(15^{\circ} \mathrm{C}\right)$, which more likely corresponds to the cold threshold. Polynomials provide more flexible functions, taking into account slopes of different signs along the trajectory and gradual changes in the slope of reaction of the traits to increasing temperatures. Moreover, cubic LP model provided a better fit of the data. In this context, the SP model will tend to overestimate the true heat stress effect because of the larger slope of decay estimated by this model compared with the LP model.

Average daily temperature showed better goodness of fit and larger slopes of decay than maximum temperature, indicating that it might be a better indicator to detect heat stress than maximum values. This might be due to the fact that the $\mathrm{T}_{\mathrm{AVE}}$ is related to minimum as well as maximum temperatures and accounts for the fact that cool night temperatures may counteract the effect of high values during the day (Igono et al., 1992). Brügemann et al. (2012) also found better goodness of fit for regression models based on an average of hourly THI than on a THI computed with daily maximal temperature and daily minimal humidity.

Quantification of the decrease (or increase) of production (or SCS) with increasing heat loads has yielded a large variety of estimates in the literature. In the 

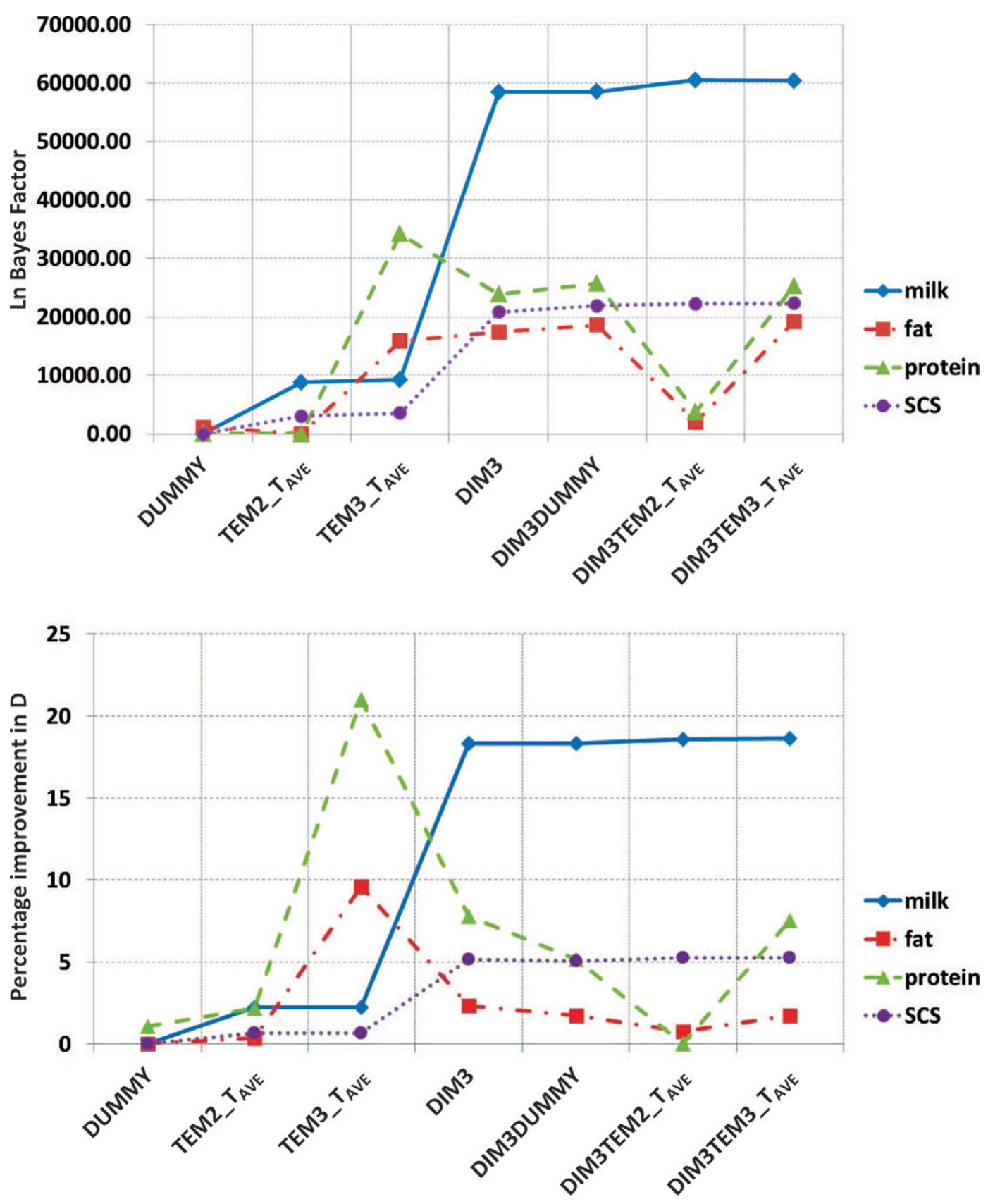

Models

Figure 6. Estimated natural logarithm of the Bayes factor of each model against the model showing the lowest marginal density and percentage of improvement with respect to the worst model in the predictive ability statistics (D) for each trait, for models including additive genetic quadratic (TEM2) and cubic (TEM3) regressions on daily average temperature $\left(\mathrm{T}_{\mathrm{AVE}}\right.$ ) or a dummy temperature variable (DIMMY) and models including an additive genetic cubic regression on DIM (DIM3) and also quadratic (DIM3TEM2) and cubic (DIM3TEM3) polynomials on $\mathrm{T}_{\mathrm{AVE}}$ or a dummy temperature variable (DIM3DUMMY), for production traits and SCS. Color version available in the online PDF.

literature searched, estimates of daily milk yield decrease ranged from $-0.08 \mathrm{~kg} / \mathrm{THI}$ at a daily average THI of 60 in a crop system of production in German Holsteins (Brügemann et al., 2012) to $-1.12 \mathrm{~kg} / \mathrm{THI}$ in a small herd of US Holstein cows in Georgia, using daily measurements of production, on-farm weather information, and cows in uniform physiological conditions in a short period of 4 mo during the spring and summer of the same year. The main factors that seem to determine this variability are the type of production 
system (mainly use or not of cooling devices and grazing versus no-grazing systems) and environment (temperate vs. hotter climates), the kind of information used (experimental/controlled data vs. commercial information), and the established heat stress threshold. In our study, the largest estimated slopes of decay were found to be $-0.17 \mathrm{~kg} /{ }^{\circ} \mathrm{C}$ and $-0.008 \mathrm{~kg} /{ }^{\circ} \mathrm{C}$ for milk and protein yields, respectively, at a $\mathrm{T}_{\mathrm{AVE}}$ of $34^{\circ} \mathrm{C}$ (THI of 79 ). For fat yield, the largest decrease was $-0.004 \mathrm{~kg} /{ }^{\circ} \mathrm{C}$ at a $\mathrm{T}_{\mathrm{AVE}}$ of $25^{\circ} \mathrm{C}$ (THI of 70) and for SCS, the largest increase was $0.0024 \mathrm{U} /{ }^{\circ} \mathrm{C}$ at a $\mathrm{T}_{\mathrm{AVE}}$ of $20^{\circ} \mathrm{C}$ ( THI of 65 ). Comparison of the estimated slopes with values found in the literature is not strictly possible due to the fact that other studies dealt with THI values that were in different scales. Nevertheless, the slopes of decay found in the current study seem to be lower than most of the previous estimates. The fact that cows participating in this study were raised in intensive conditions that often included cooling devices and the acclimation of animals to hot conditions along the summer might be causes for the relatively small effect of high temperatures on production. On the other hand, the use of test-day commercial data to estimate the effect of high heat loads on production may not be optimal because of the noisy nature of this information. Nuisance factors, such as variation in management and housing characteristics, across herds and periods and variation due to lactation stage and physiological status of the cows as well as their interaction with heat effects need to be removed to obtain accurate estimates of heat stress on production and SCS. However, these factors are not always easy to take into account and estimated responses from these studies ought to be made with caution. In this line of thought, Freitas et al. (2006) obtained the mentioned decay of $-1.12 \mathrm{~kg} / \mathrm{THI}$ for a sample of 31 primiparous Holstein cows from April 28 to July 19, 1993, using daily records of 2 milkings per day, whereas the same study reported the largest decay of $-0.22 \mathrm{~kg} /$ THI in subsequent analyses including 2,260 test-day (monthly) records from the same farm from 1993 to 2003 and weather data from a nearby station, as in commercial conditions. Those authors conclude that, compared with daily recording, "the test days provide a very limited snapshot of heat stress" and that "better accounting for heat stress with test days could be obtained by pooling farms with a similar management and using more frequent recording."

Modeling the genetic component of the individual response to increasing heat loads has been less studied than the phenotypic response. Most of the studies (Ravagnolo and Misztal, 2000; Bohmanova et al., 2005; Finocchiaro et al., 2005; Aguilar et al., 2009; Sánchez et al., 2009a,b; Bernabucci et al., 2014) applied a threshold and slope approach, as initially suggested in Misztal
(1999). Only recently have Brügemann et al. (2011) applied a random regression polynomial function to the additive genetic components of response to heat load. No studies have compared both approaches. In our study, comparisons were done under a goodness-of-fit and a predictive ability criterion within the Bayesian framework. Ranking of models differed across traits and statistical criteria. For milk and SCS, both criteria pointed at the DUMMY model, the threshold and slope model with no adjustment of individual random regression components along DIM, as the worst model. The best models were those including DIM3 regressions, the traditional test-day model, with small improvements by adding regressions on temperature. This result agrees well with the small fraction (3-10\%) of the variance in lactation milk production found to be associated with climatic factors mentioned by Kadzere et al. (2002) in their review article. For fat and protein yields, ranking of models differed, depending on the comparison criteria. The TEM3 model was the preferred model from a predictive ability perspective, whereas DIM3TEM3 was best for fat yield and DIM3DUMMY for protein yield in terms of goodness of fit. The predictive ability criterion tends to select more parsimonious models, avoiding complexities that may fit the data well, but fail in obtaining a good prediction of future observations. Therefore, a genetic evaluation model for heat tolerance of fat or protein yield in this population would not require the complexity of adding the random regression reaction norm for temperature on top of the regular test-day model, whereas for milk or SCS, the regression on DIM seems to be needed.

The estimation of the individual genetic components in the response to heat stress under all models revealed 2 interesting features of the genetics of heat stress in this population. One is the existence of $\mathrm{G} \times \mathrm{E}$ interactions and the other is the possibility of selection for tolerance to heat stress independent of production.

Genotype by environment interaction under varying heat loads was indicated by the non-unity genetic correlation between genetic values at low and high temperatures and by the variability in the patterns of EBV across temperatures. Evidence for $\mathrm{G} \times \mathrm{E}$ interactions was stronger for animals showing high genetic potential for production. These animals tended to show decreasing estimated genetic values at higher temperatures, which implies that top-ranked animals at cold or comfort temperatures might be expected to perform poorly under heat stress. Response to heat stress was also affected by lactation stage. Estimates of genetic correlations were lowest around lactation peak (represented by values at 50 DIM in this study). These 2 results add evidence to the antagonistic relationship between high production and tolerance to heat stress that has been 
described in other studies (see, for example, Kadzere et al., 2002; Collier and Zimbelman, 2007). This antagonism derives from the increased heat production under the high metabolic activity implied by high levels of production. Therefore, the increase in metabolic heat associated with higher production might be one of the major components of heat susceptibility in Holstein dairy cattle. This is in agreement with the negative correlation between level of production and heat stress tolerance (slope in DUMMY models or linear coefficient in polynomials) obtained in this and other studies (Ravagnolo and Misztal, 2000; Aguilar et al., 2009; Sánchez et al., 2009a; Bernabucci et al., 2014).

All these results indicate that selection for high production might reduce the tolerance to heat stress, and vice versa. Therefore, it seems important to find selection criteria that allow increases in heat tolerance without a negative effect on production. In this context, the possibility of using the canonical variables resulting from the eigendecomposition of the additive genetic random regression coefficient (co)variance matrices may provide useful tools for independent selection. In this study, the canonical variable explaining the largest fraction of the variability in the genetic values of animals across temperatures was the overall production level across temperatures. As mentioned in the Results section, this proportion was highest for milk yield and lower for fat and protein yield and SCS. The implication of these results is that only a small proportion (around 10\%) of the variability in milk production across temperatures is not linked to the level of production, but a much larger variability, independent of the level of the trait for milk components and SCS, can be exploited to select animals tolerant to heat stress. One of the canonical variables, explaining up to $24 \%$ of the overall variability for fat and protein content and SCS, could be considered as a selection criterion for tolerance to heat stress, independent of the overall level of production for those traits. Genomic information may play a major role in disentangling the production and nonproduction components of heat tolerance by identifying genomic variants present in animals showing high levels of production and small slopes of decay and exploring the genomic regions associated with the canonical components that are not associated with production level.

\section{CONCLUSIONS}

In this study, production losses and increases in SCS due to heat stress in hot and dry conditions were in the low range of values found in the literature for other Holstein populations under similar climatic conditions in the United States or Italy and more in the range of values found for Holstein cows in more temperate climatic conditions in Europe. The intensive system of production and the possible acclimation of animals to steady weather conditions during the summer months might be possible reasons for the relatively low decays. Polynomial functions provided sounder patterns and better goodness of fit than the SP model to describe changes in production and SCS along the range of studied temperatures at the phenotypic level as well as for the individual components. The pattern of phenotypic response to temperature for milk differed from the flat and linear decay model because decay was found for low as well as for high temperatures. For fat yield, production was not constant before the threshold, but tended to decrease slightly from the beginning and more abruptly after the threshold. A consequence of the use of the threshold and slope approach might be the overestimation of heat stress effect, particularly if the true comfort threshold is larger than the estimated value. This seemed to be the case in this study. This study provides evidence of a $\mathrm{G} \times \mathrm{E}$ interaction between production and SCS and temperature. This interaction is expected to be larger for milk components and SCS than for milk volume. Moreover, the fact that the EBV of the best animals for production showed a trend to decrease for high temperatures confirms the antagonistic relationship between production level and tolerance to heat stress found in other studies. Most of the variability in milk yield across the range of studied temperatures was associated with differences in level of production of the animals, indicating that selection for tolerance to heat stress in this trait may not be very efficient. On the other hand, for fat and protein yield, variability independent of level of production was substantial. For these traits, a cubic polynomial on temperatures for the additive genetic and permanent environmental effects showed the best features. The use of the second eigenfunction of the estimated additive genetic (co)variance matrix for this model showed a potential interest for use as a selection criterion to improve tolerance to heat stress independently of the production level. For SCS, a large proportion of the variability of response to temperature independent of the level individual SCS was also found, but inclusion of regressions on DIM as well as temperature would be required.

\section{ACKNOWLEDGMENTS}

This study was financed by the project INIA-FEDER RTA2011-00108. The authors thank Agencia Estatal de Meteorologia (AEMET; Madrid, Spain) for providing the meteorological records, the Confederation of the Spanish Friesian Associations (CONAFE; Madrid, Spain) for providing the production and somatic cell 
counts data as well as pedigree information, and Juan Pablo Sánchez (Genètica i millora animal, IRTA, Torre Marimon, Caldes de Montbui (Barcelona), Spain) for providing the software to estimate the threshold and slope of response to heat stress at the population level.

\section{REFERENCES}

AEMET (Agencia Estatal de Meteorología). 2011. Iberian Climate Atlas. Air temperature and precipitation (1971-2000). Ministerio de Medio Ambiente y Medio Rural y Marino, Instituto de Meteorologia de Portugal. Accessed Dec. 20, 2013 http://www.aemet.es/ documentos/es/conocermas/publicaciones/Atlas-climatologico/ Atlas.pdf.

Aguilar, I., I. Misztal, and S. Tsuruta. 2009. Genetic components of heat stress for dairy cattle with multiple lactations. J. Dairy Sci. 92:5702-5711.

Ali, A. K. A., and G. E. Shook. 1980. An optimum transformation for somatic cell concentration in milk. J. Dairy Sci. 63:487-490.

Bernabucci, U., S. Biffani, L. Buggiotti, A. Vitali, N. Lacetera, and A. Nardone. 2014. The effects of heat stress in Italian Holstein dairy cattle. J. Dairy Sci. 97:471-486.

Bohmanova, J., I. Misztal, and J. B. Cole. 2007. Temperature-humidity indices as indicators of milk production losses due to heat stress. J. Dairy Sci. 90:1947-1956.

Bohmanova, J., I. Misztal, S. Tsuruta, H. D. Norman, and T. J. Lawlor. 2005. National genetic evaluation of milk yield for heat tolerance of United States Holsteins. Interbull Bull. 33:160-162.

Brügemann, K., E. Gernand, U. König von Borstel, and S. König. 2012. Defining and evaluating heat stress thresholds in different dairy cow production systems. Arch. Tierzucht 55:13-24.

Brügemann, K., E. Gernand, U. U. von Borstel, and S. König. 2011. Genetic analyses of protein yield in dairy cows applying random regression models with time-dependent and temperature $\times$ humidity-dependent covariates. J. Dairy Sci. 94:4129-4139.

Collier, R. J., L. W. Hall, S. Rungruang, and R. B. Zimbleman. 2012 Quantifying heat stress and its impact on metabolism and performance. Pages 74-83 in Proc. Florida Ruminant Nutrition Symp., University of Florida, Gainesville

Collier, R. J., and R. B. Zimbelman. 2007. Heat stress effects on cattle: What we know and what we don't know. In Proc. of the Southwest Nutrition and Management Conference, The University of Arizona, Tucson. Accessed May 1, 2014. http://ag.arizona.edu/ans/ swnmc/Proceedings/2007/Collier_2007SWNMC.pdf.

Finocchiaro, R., J. B. C. H. M. van Kaam, B. Portolano, and I. Misztal. 2005. Effect of heat stress on production of Mediterranean dairy sheep. J. Dairy Sci. 88:1855-1864.

Freitas, M. S., I. Misztal, J. Bohmanova, and J. West. 2006. Utility of on- and off-farm weather records for studies in genetics of heat tolerance. Livest. Sci. 105:223-228.

Hammami, H., J. Bormann, N. M'hamdi, H. H. Montaldo, and N Gengler. 2013. Evaluation of heat stress effects on production traits and somatic cell score of Holsteins in a temperate environment. J. Dairy Sci. 96:1844-1855.
Igono, M. O., G. Bjotvedt, and H. T. Sanford-Crane. 1992. Environmental profile and critical temperature effects on milk production of Holstein cows in desert climate. Int. J. Biometeorol. 36:77-87.

Jamrozik, J., and L. R. Schaeffer. 1997. Estimates of genetic parameters for a test day model with random regression for production of first lactation. J. Dairy Sci. 80:762-770.

Kadzere, C. T., M. R. Murphy, N. Silanikove, and E. Maltz. 2002. Heat stress in lactating dairy cows: A review. Livest. Prod. Sci 77:59-91.

Kass, R. E. 1993. Bayes factors in practice. Statistician 42:551-560.

Kirkpatrick, M., D. Lofsvold, and M. Bulmer. 1990. Analysis of the inheritance, selection and evolution of growth trajectories. Genetics 124:979-993.

López-Romero, P., R. Rekaya, and M. J. Carabaño. 2003. Assessment of homogeneity vs. heterogeneity of residual variance in random regression test-day models in a Bayesian analysis. J. Dairy Sci. 86:3374-3385

Misztal, I. 1999. Model to study genetic component of heat stress in dairy cattle using national data. J. Dairy Sci. 82(Suppl. 1):32 (Abstr.)

Misztal, I., S. Tsuruta, T. Strabel, B. Auvray, T. Druet, and D. H Lee. 2002. BLUPF90 and related programs. Commun. No. 28-07 in Proc. 7th World Congr. Genet. Appl. Livest. Prod., Montpellier, France.

NRC. 1971. A Guide to Environmental Research on Animals. Natl. Acad. Sci., Washington, DC.

Ravagnolo, O., and I. Misztal. 2000. Genetic component of heat stress in dairy cattle, parameter estimation. J. Dairy Sci. 83:2126-2130.

Sánchez, J. P., I. Misztal, I. Aguilar, B. Zumbach, and R. Rekaya. 2009a. Genetic determination of the onset of heat stress on daily milk yield in US Holstein cattle. J. Dairy Sci. 92:4035-4045.

Sánchez, J. P., R. Rekaya, and I. Misztal. 2009b. Reaction norm model subject to threshold response for genetic evaluation on heat tolerance. Genet. Sel. Evol. 41:10.

Segnalini, M., U. Bernabucci, A. Vitali, A. Nardone, and N. Lacetera 2013. Temperature humidity index scenarios in the Mediterranean basin. Int. J. Biometeorol. 57:451-458.

Smith, B. J. 2007. boa: An R package for MCMC output convergence assessment and posterior inference. J. Stat. Softw. 21:1-37.

Smith, D. L., T. Smith, B. J. Rude, and S. H. Ward. 2013. Short communication: Comparison of the effects of heat stress on milk and component yields and somatic cell score in Holstein and Jersey cows. J. Dairy Sci. 96:3028-3033.

Spiegelhalter, D., N. Best, B. Carlin, and A. van der Linde. 2002. Bayesian measures of model complexity and fit. J. R. Stat. Soc., B 64:583-639.

Togashi, K., and C. Y. Lin. 2006. Selection for milk production and persistency using eigenvectors of the random regression coefficient matrix. J. Dairy Sci. 89:4866-4873.

Zimbelman, R. B., R. P. Rhoads, M. L. Rhoads, G. C. Duff, L. H Baumgard, and R. J. Collier. 2009. A re-evaluation of the impact of temperature humidity index (THI) and black globe humidity index (BGHI) on milk production in high producing dairy cows. Pages 158-168 in Proc. Southwest Nutr. Manag. Conf., Tempe, AZ. The American Registry of Professional Animal Scientists (ARPAS), Savoy, IL 